\title{
Ethical Considerations: Scar Management
}

Clarisse Ganier and Sonia Gaucher

\section{Contents}

20.1 Is there Truly a Need to Invoke Ethics When the Clinician Is Faced with Managing a Patient's Scar? - 180

20.2 What Are the Dilemmas that a Clinician Will Confront in Their Daily Practice When Managing a Patient's Scar? - 180

References - 181 
The purpose of this chapter is to provide an overview and potential answers to the ethical considerations of the clinical management of patient scars. We will focus on two main aspects of this subject:

1. Is there truly a need to invoke ethics when the clinician is faced with managing a patient's scar?

2. What are the dilemmas that a clinician will confront in their daily practice when managing a patient's scar?

\subsection{Is there Truly a Need to Invoke Ethics When the Clinician Is Faced with Managing a Patient's Scar?}

The motivation for the clinical management of a patient's scar from both the patient's perspective and the clinician's perspective is clear: first, to improve the appearance of the scar and, second, if needed, to improve any functional impairment that the scar may have caused. If successful, these goals will enhance the beauty and function of the patient's skin and improve the patient's quality of life. Therefore, like all therapies or procedures in medicine, the ethical considerations of scar management are based upon balancing the risks and benefits of any treatment.

There are multiple causes of scars - scars generated by unintended accidents, iatrogenic scars from surgical procedures, and even self-inflected voluntary scars created by the patient. The constant among these, regardless of the reason(s) of the scar, is that the skin has been injured and has undergone the known phases of wound healing - clotting with platelet aggregation and activation, inflammation, reepithelialization, fibroplasia, neovascularization, granulation tissue formation, and then a long period of tissue remodeling with fibrosis and scarring. The scar is actually a witness to these events of "reparative" wound healing, rather than "regenerative" non-scarring wound healing that is seen in newts and lower animals.

Each cultural group has its own concept of beauty and of what it considers to be normal or aberrant. Moreover, the judgment of what is normal or not may be interpreted differently, not only by the society but also by the individuals. That is why when a patient bears a scar, it may take on different meanings, depending upon the societal and individual context of the scar.

Sometimes, a skin scar can carry a highly positive message. For example, the scar could be proudly exhibited as a testimony of some glorious actions such as the mark of a successful warrior exploit or survival from a savage assault. A voluntarily induced scar could also represent a ritualistic marking that symbolizes both social allegiance and beauty. Examples include scarifications and tattoos.

Conversely, a skin scar could represent an echo of an emotional scar. In these situations, the meaning of the scar is well beyond a simple previous threat to the integrity of the body envelope. Rather, the scar becomes a permanent remembrance a traumatic event. The scar may represent and even support the revival of the patient's spirit after a painful traumatic episode. The possibility of recognizing an aesthetic prejudice, which could be temporary and/or permanent, in the context of a judicial expertise, testifies to this aspect.

On the other hand, for patients whom are strictly compliant to societal standards and societal points of view of beauty, a scar in a visible location on the patient's body may cause loss of self-esteem and self-confidence, regardless of its origin.

Another potential context of scar management would be a patient who generates and accumulates self-inflicted scars and psychologically believes that the healed scars form sort of protective bandage.

Therefore, there is no single approach to the management of these various complex situations, except for the underlying understanding that patients who are scarred require attention, and a physician who listens to them assesses the proper context of the scar and considers carefully what the patient desires.

\subsection{What Are the Dilemmas that a Clinician Will Confront in Their Daily Practice When Managing a Patient's Scar?}

At the same time, the surgeon may be pleased to observe a minimal scar as the result from his/her surgical procedure and may be faced with the disappointed patient who wants the scar to disappear completely.

In many cases - and especially after surgery - scars can make the physician feels uncomfortable, because the scar is an obvious evidence of the physician's work and reminds the physician of his or her limitations and shortcomings. Totally scarless surgery is not possible. Beyond the disease that the patient would like to forget and beyond the pain and suffering that the patient went through, the physician needs to understand the disappointment and distress of the patient when he/she learns that the scar is permanent and cannot be erased.

Experience has taught us that objective criteria (surface area, surface texture, color, thickness, degree of fibrosis etc.) are not always sufficient to assess adequately a scar and its functional and psychological repercussions. A too fast clinical examination and judgment may lead to the conclusion that the patient's request for scar revision is superfluous, unnecessary, or even unreasonable. To avoid misunderstanding of the patient's feeling and desire for scar revision, the physician must look beyond the simple appearance of the scar and has to harken back to the patient's own history including his or her trauma 
and the context of the scar. A large discrepancy between the perspective of the patient and the perspective of the physician might be an early indication of psychological difficulties and a call for further clinical attention [1].

When the patient adamantly demands scar revision by surgical intervention, it often comes from the patient's point of view (and/or experience) that less invasive solutions (topical steroids, silicone membranes, laser treatment, etc.) are not satisfactory.

The origin of surgical ethics is uncertain $[2,3]$. Reviews and studies on skin scar ethics are scarce [4]. Most of the articles involve issues related to the ethics of burn scars [5], the ethics in plastic surgery [6], or the ethics in major surgery [7]. Nevertheless, some reviews highlight the current problems associated with emerging approaches for scar management such as the use of fetal cells in skin regeneration [8].

According to Miles Little publications [9, 10], surgical ethics have generally been framed as general medical ethics applied to surgical situations. There are five categories of experience and relationship, which are especially important in surgery field. These include (i) rescue, (ii) proximity, (iii) ordeal, (iv) aftermath, and (v) presence. The sense of rescue and of relational proximity, the ordeal, and aftermath of surgery are things that the patient experiences. Understanding these feelings allow surgeons to know what may be asked of them in an ethical point of view. Recognition of the reality and validity of each category in the surgical process highlights the importance of presence that is the acts by which the surgeon demonstrates that he is present to the patient throughout the surgical process and its consequences. While communication skill trainings may never completely compensate for insensitivity, the ideal of presence as a virtue and as a duty can be taught by precept and by mentors.

As Albert Einstein said "If you always do what you always did, you will always get what you always got." Because each scar, each patient, and each context are unique, the search for an adequate and appropriate surgical solution constantly forces us to innovate. Innovation in surgery has contributed to progress in medicine and has enhanced the overall patient's quality of life. Nevertheless, surgical innovation itself also raises numerous ethical issues, such as patient safety, informed consent, the proper use of healthcare resources, and conflicts of interest - especially in the case of developing new devices by an industry-physician partnership. None of these challenges are specific to surgery field, nor to scars, but there are features about surgery and scars that complicates the identification and resolution of these issues $[11,12]$. Therefore, it is important, from an ethical point of view, to consider that innovation is not only the key to progress but also the greatest challenge to our professionalism [13].

\section{- Take Home Message \\ Given that scar treatment needs to balance risks and benefits for the patient, it's impossible to define a skin scar by its physical appearance only.}

\section{References}

1. Hoogewerf CJ, Van Baar ME, Middelkoop E, Van Loey NE. Patient reported facial scar assessment: directions for the professional. Burns. 2014;40(2):347-53.

2. Namm JP, Siegler M, Brander C, Kim TY, Lowe C, Angelos P. History and evolution of surgical ethics: John Gregory to the twenty-first century. World J Surg. 2014;38(7):1568-73.

3. Pellegrini CA, Ferreres A. Surgical ethics symposium "ethical dilemmas in surgical practice". World J Surg. 2014;38(7):1565-6.

4. Ferreres A, Angelos P. Surgical ethics symposium: ethical dilemmas in surgical practice. World J Surg. 2014;38(7):1567.

5. Teven CM, Gottlieb LJ. The four-quadrant approach to ethical issues in burn care. AMA J Ethics. 2018;20(6):595-601.

6. Sterodimas A, Radwanski HN, Pitanguy I. Ethical issues in plastic and reconstructive surgery. Aesthet Plast Surg. 2011;35(2):262-7.

7. Wall AE. Ethics in global surgery. World J Surg. 2014;38(7): 1574-80.

8. Li Q, Zhang C, Fu X. Will stem cells bring hope to pathological skin scar treatment? Cytotherapy. 2016;18(8):943-56.

9. Little M. The fivefold root of an ethics of surgery. Bioethics. 2002;16(3):183-201.

10. Little M. Invited commentary: is there a distinctively surgical ethics? Surgery. 2001;129(6):668-71.

11. Johnson J, Rogers W. Innovative surgery: the ethical challenges. J Med Ethics. 2012;38(1):9-12.

12. Miller ME, Siegler M, Angelos P. Ethical issues in surgical innovation. World J Surg. 2014;38(7):1638-43.

13. Angelos P. Ethics and surgical innovation: challenges to the professionalism of surgeons. Int J Surg. 2013;11(S1):S2-5.

Open Access This chapter is licensed under the terms of the Creative Commons Attribution 4.0 International License (http://creativecommons. org/licenses/by/4.0/), which permits use, sharing, adaptation, distribution and reproduction in any medium or format, as long as you give appropriate credit to the original author(s) and the source, provide a link to the Creative Commons license and indicate if changes were made.

The images or other third party material in this chapter are included in the chapter's Creative Commons license, unless indicated otherwise in a credit line to the material. If material is not included in the chapter's Creative Commons license and your intended use is not permitted by statutory regulation or exceeds the permitted use, you will need to obtain permission directly from the copyright holder. 